SCIREA Journal of Education

http://www.scirea.org/journal/Education

October 19, 2021

Volume 6, Issue 5, October 2021

\title{
Distance Teaching Mode and Practices in College English Course during COVID-19 Pandemic Crisis in China
}

\author{
Wang Lili \\ School of Modern Science and Technology, China Jiliang University, Hangzhou, Zhejiang, \\ China
}

\begin{abstract}
During the COVID-19 pandemic in early 2020, many Chinese colleges and universities actively carry out distance online teaching, responding to the call of the Ministry of Education to "suspend classes without suspension of teaching and learning." However, the integration of the Internet and education has changed the traditional education ecology and has also posed a huge challenge to the traditional teaching model. The research focuses on the teaching practices of on-line teaching of College English course and offers a detailed analysis of the changed teaching model adopted by China Jiliang University. The paper employs both quantitative and qualitative approaches to study the perceptions of teachers and students during the lockdown period, trying to construct a new online teaching mode by taking both of the feedback of students and the teaching reflection of teachers into consideration. It is hoped that the research results can provide some enlightenments for colleges and universities to deal with emergencies and expand online higher education in the future.
\end{abstract}


Keywords : COVID-19 Pandemic ; Distance Teaching Mode ; Feedback ; Teaching Reflection

\section{Acknowledgement:}

This article is the research results of the key project of the Education Management Center of the Ministry of Education in 2017, "Research on Flexible Teaching Strategies of Blended Learning for College English" (No. EIJY2017-031) and China Jiliang University's 2019 school-level Teaching Reform Project "The Research on the Integration Model of Translation MOOC and English Classroom Teaching" (No. HEX2019031).

\section{BACKGROUND}

During the pandemic crisis in early 2020, in order to implement the spirit of the important instructions of our general secretary and respond to the call of the Ministry of Education to "suspend classes without stopping teaching and learning", most universities in China have conducted distance online teaching-learning practices. In the second semester of 2019-2020, in order to ensure the health and life safety of teachers and students, China Jiliang University, which the author has worked for, has actively implemented online teaching preparations before the end of the winter vacation by Urging every teacher to use the spare time of the winter vacation to prepare online courses to ensure that the learning will not be suspended due to the impact of the pandemic crisis. In the past, due to participations in education reform projects at all levels, the author has opportunities to organize several "flipped classroom" teaching practices, combining online resources, platform utility with the advantages of offline courses. However, until then, the author has no experience of conducting distance online teaching. 


\section{AN INTRODUCTION TO THE PROBLEMS OF DISTANCE}

\section{TEACHING MODE}

The main teaching task of the author in the semester is the teaching of College English II and College English III. The next semester of the first grade is one of the most critical semesters for students who want to pass CET-4 and CET-6. Not only must the freshmen complete the teaching content of the two books according to the syllabus, but also participate in CET-4 and CET-6. The level examinations are designed to test the learning effects of the course. How to make online teaching achieve the teaching quality of offline classrooms undoubtedly poses psychological challenges to teachers. At the same time, the integration of the Internet and education has changed the traditional education ecology and has also posed a huge challenge to the traditional teaching mode. [1]

\subsection{The Challenges of Distance Teaching Mode}

The following problems need to be solved urgently:

1. What platform should teachers choose for online teaching?

2. Are the existing teaching content and materials suitable for online teaching?

3. If the existing materials are not suitable, how to collect the required materials?

4. How should teachers effectively supervise students' learning?

5. How should the teacher get in touch with the students in the course and communicate in time?

\subsection{The Countermeasures of the Problems}

The pressure is greater, the motivation is greater. At the beginning of February, after receiving the notice of "suspending classes" and arrangement of "conducting distance online teaching" from the university, the author has already taken active actions during the winter vacation to look for countermeasures accordingly.

1. The course team set up a We-chat group to discuss which platform should be used in online teaching and analyzed the pros and cons of different platforms. 
TABLE 1 Analysis of the pros and cons of learning platforms

\begin{tabular}{|c|c|c|c|}
\hline $\begin{array}{c}\text { Teaching } \\
\text { Platform }\end{array}$ & $\begin{array}{c}\text { Teaching } \\
\text { Forms }\end{array}$ & Pros & Cons \\
\hline $\begin{array}{c}\text { Chaoxing } \\
\text { Learning }\end{array}$ & $\begin{array}{c}\text { Live } \\
\text { broadcast/record } \\
\text { ing }\end{array}$ & $\begin{array}{c}\text { interaction, course construction } \\
\text { function }\end{array}$ & easy to freeze \\
\hline $\begin{array}{c}\text { Rain } \\
\text { classroom }\end{array}$ & $\begin{array}{c}\text { Live } \\
\text { broadcast/record } \\
\text { ing }\end{array}$ & $\begin{array}{c}\text { interaction, course construction } \\
\text { function }\end{array}$ & easy to freeze \\
\hline $\begin{array}{c}\text { Ding Talk } \\
\text { broadcast/record } \\
\text { ing }\end{array}$ & $\begin{array}{c}\text { smooth live broadcast and } \\
\text { homework correction }\end{array}$ & no course \\
\hline $\begin{array}{c}\text { Blackboard } \\
\text { learning }\end{array}$ & recording only & $\begin{array}{c}\text { campus platform and automatic } \\
\text { logging }\end{array}$ & $\begin{array}{c}\text { no live broadcasting } \\
\text { function }\end{array}$ \\
\hline $\begin{array}{c}\text { ZJOOC } \\
\text { Platform }\end{array}$ & recording only & $\begin{array}{c}\text { Mass course resources and course } \\
\text { building function }\end{array}$ & $\begin{array}{c}\text { no live broadcasting } \\
\text { function }\end{array}$ \\
\hline
\end{tabular}

(P.S. ZJOOC Platform refers to Zhejiang institutions of higher learning open course sharing platform.)

After several rounds of discussions with colleagues, the course team selected Ding Talk platform and started to build courses separately.

2. According to the syllabus, the teachers of the team improved the content of online teaching by making full use of existing materials and online resources, started to sort out the past teaching materials and teaching material and study how to redesign the teaching content to meet the basic requirements and characteristics of online courses.

3. On the basis of the existing teaching material, testing and question sessions are added to the teaching content in order to enhance the interactive effects to make the courses more in line with the characteristics of online courses. At the same time, the team members actively seek out high-quality online resources to expand and supplement existing teaching content.

4. Teachers learned to use the interactive functions on the learning platform to supervise students' learning conditions.

5. Instructors set up a WeChat group for the class as soon as possible to facilitate timely contact with students. 


\section{PRECLASS PREPARATION FOR DISTANCE TEACHING}

At present, the teaching practices of the semester have been completed. The current teaching model and system are operating well, and the learning effect is fully guaranteed. The main reason is sufficient pre-class preparation. What learning materials should be used in class, what teaching platform should be used, and how should teaching supervision work? How to effectively carry out distance teaching activities? If these problems are not resolved before the start of the class, they will directly affect the teaching process and teaching effects. The author was able to successfully complete the teaching task of the semester during the pandemic crisis, mainly because of the following four aspects of support: the guidance of college leaders, the information sharing among colleagues, the feedback from students and the enormous resources on the Internet.

\subsection{The Guidance of College Leaders}

The leaders of School of Modern Science and Technology that the author works in command properly, provide teaching guidance in time, and help teachers understand how to use each platform. As early as the outbreak of the epidemic, they made full preparations: all teachers are required to become familiar with mainstream online teaching platforms as soon as possible, such as Chaoxing Learning, Rain Classroom, Ding Talk and etc.; invite Professors with online teaching experiences inside and outside the school to provide online guidance to all teachers; make detailed arrangements for the specific matters of the online semester, and urge all teachers to make specific preparations for respective courses, etc. Their meticulous and comprehensive mobilization and preparation successfully helped all teachers face up to the sudden epidemic situation, and succeeded in overcoming emergent difficulties without panic.

Fortunately, Professor Lu Sa of our school is a pioneer in online teaching, who has the teaching experiences of provincial and national quality online courses. With rich experiences and skills in online teaching, she has no reservations and devoted herself to help all the teachers to understand and manipulate the various methods of classroom interactions by Ding Talk and Rain Classroom live broadcast. 
After comprehensively considering the pros and cons of each platform, College English course group decided to use the Ding Talk platform for live teaching. Teaching practice in the three weeks after the start of semester proves that although Ding Talk does not have system building and data editing functions for the time being, it can guarantee the application of the live broadcast function during the peak period, which is very valuable in this special period.

After subsequent development, Ding Talk also has many more powerful functions than other learning platforms: such as the notification function, which can not only quickly ding information to students, but also check the number of readers, and at the same time allow teachers to remind students who have not read in time. And the replay function in Ding Talk is very useful, by which the teacher can completely store the teaching content of the course, and students are enabled to review the classes unlimitedly, which ensure that if students encounter unexpected situations such as power outages, disconnection, etc., those emergencies will not affect their learning.

However, the most striking feature of Ding Talk is the English homework correction function. During the epidemic, Ding Talk specially developed the "English homework" function, which can help students point out basic grammar and syntax problems in the compositions, which meets the actual needs of distance online teaching. After Ding Talk's English homework correction function was launched, the author has arranged a composition for each class. Most students of the author's classes report that it is very convenient to use, and can also help them modify the compositions for many times, which undoubtedly helps them improve writing ability effectively.

\subsection{The Information from Colleagues}

Information sharing among colleagues effectively solves many practical problems in distance online teaching. In order to facilitate teaching communication, the course team has established a WeChat group, where topics related to teaching content, teaching methods, and teaching reflection are often discussed in the group. During the current epidemic crisis, the 
WeChat group has become a cooperative and mutual assistance channel for teachers to share resources and offer timely supports to each other.

Before the start of the special semester, a number of teachers communicated with each other in the group on topics such as the selection and arrangement of teaching content, platform usage, recording operation, and selection of materials for the expanded part, which effectively solved many detailed problems in online teaching.

\subsection{The Feedback from Students}

The interactions in the Student WeChat group enable teachers obtain the feedback in time, which helps to soothe students' anxiety in distance learning. Through the previously established WeChat group, teachers can inquire about students' psychological status and learning needs, and adjust teaching content and teaching modes accordingly in time. Knowing the emotional anxiety of students in the early stage of studying at home, the author made a few arrangements before the start of the semester:

First, send the online textbooks to students via the Internet to ensure that every student has the most basic learning material— the online textbook.

Secondly, set up a study group and choose a monitor as the group leader. Students can communicate with teachers timely in a friendly manner in the new class WeChat group, so that they can get timely feedback from teachers if they have any questions.

Finally, in the WeChat group, timely notify the specific arrangements of online teaching, and publicly inform the students of the learning tasks and release time. Specific learning tasks can help students focus on learning and effectively help them relieve anxiety.

\subsection{The Enormous Resources on the Internet}

The full use of network resources helps teachers quickly integrate online teaching content. The author carefully referred to the resources provided by some authoritative publishing houses such as "Basic English Writing" and "College English" to effectively supplement textbook knowledge and assist teaching, kept watching the teaching videos shared by some outstanding teachers from other universities on Zhejiang institutions of higher learning open 
course sharing platform and learned as many as teaching technological methods as possible to constantly update knowledge reserves, prepare and record lessons in time to prevent network failures in the live broadcast.

\section{THE DETAILED ANALYSIS OF DISTANCE TEACHING MODE}

Although many preparations have been made before the start of the semester, such as the teaching content has been recorded, the teaching expansion materials have been stored, at least one month of course construction has been completed on the learning platform, and the tests of online live broadcast of Ding Talk and online meetings have been completed. However, how to manage online classrooms is still a severe challenge for most teachers.

The pandemic helped teachers fully understand the differences among the teaching modes in traditional classrooms, flipped classrooms and online classrooms.

In the traditional classrooms, teachers can interact with students in real-time and have face-to-face communications at the podium without relying on the support of mobile phones and the Internet to complete the tasks of teaching supervision.

The teaching mode of "flipped classrooms" is an evolution of the traditional one. Teachers can put the main teaching content on the network platform and ask students to watch it after class. Teachers can spend most of the classroom time on the discussion of teaching content, in-depth explanations and teacher-student interactions, which can enrich and expand the teaching content and employ teaching methods to a large extent.

When it comes to the teaching in online classrooms, because of the lack of physical space and real-time interactions during the pandemic, it is difficult to achieve the same teaching effects of classroom supervision and on-site interactions as in the offline classrooms, and it is also difficult to ensure students' initiative participation. Undoubtedly, the learning effect of online courses largely depends on students' self-management ability.

In the current online teaching ecology, the learning methods of learners and educators must be transformed from a single method in the past to a hybrid teaching and learning method 
that has the advantages of individualization, convenience, and abundant resources [2]. Therefore, teachers must reflect on the current teaching mode and education management in order to ensure the orderly progress of distance teaching. In the following part, the author tries to explain the transformation of teaching mode in this semester from the aspects of course content presentation, sign-in mode, interactive mode, homework processing, and network construction.

\subsection{The Presentation of the Content}

Online teaching is different from offline teaching. In order to prevent problems in live broadcast and ensure students' concentration, the content of the course is best presented in the form of short and succinct micro-classes. The author encountered many difficulties and challenges in the preparation process of the micro-classes. Because there is a lot of interference in the recording at home and lack of students' interaction, the author often encountered the problems of typos, inappropriate pauses, repeated hoarseness of the vocal cords, and the distractions of background noises. As long as there is a problem, the teacher will have to repeat everything to record again and again, which is a great challenge for most teachers when dealing with online teaching.

The long-term preparation of micro-classes has also made the author a lot of gains. I realize that about the design of micro-classes, enough attention should be paid to the following points:

First of all, the content of micro-classes should be streamlined and pay attention to the "ten-minute limit", which means that important teaching knowledge points should be condensed within ten minutes.

The American MOOC platform edX has done a famous data test: the median time that users actually watch online micro-classes is no more than 6 minutes. A video length of less than 10 minutes is more appropriate. [3] 


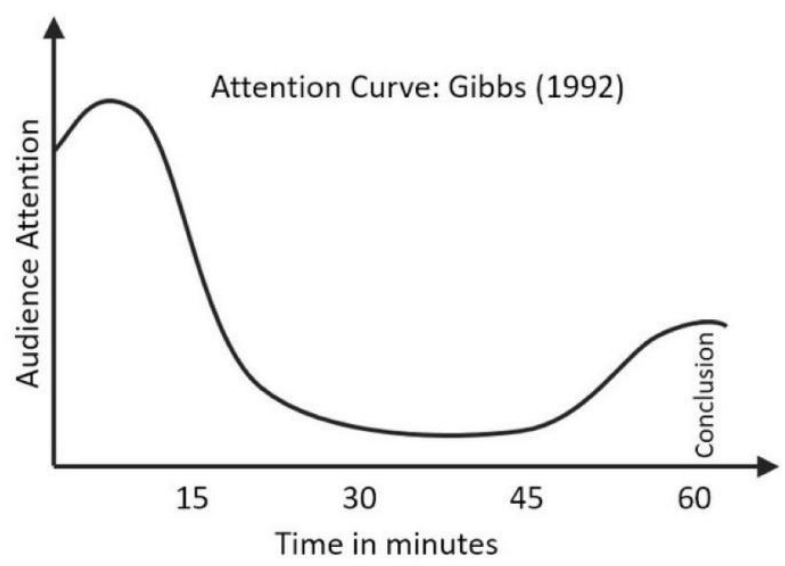

FIGURE 1 Video length and attention curve

Secondly, the presentation format of the micro-class should be as close to the offline teaching mode as possible, not only to teach knowledge points, but also to leave some spare time for students to think and absorb.

Finally, after explaining the knowledge points, the teacher should prepare a few more questions for students to think, in order to examine the students' mastery of the knowledge points. With the addition of the imaginary teacher-student interactions, the screen recording work would become less boring.

\subsection{The Method of Signing-in}

Classroom teaching activities need to ensure the number of students participating in remote classroom learning. The Ding Talk live broadcast finally used by our teaching group has an automatic statistics function after the live broadcast of the course is over. It will also be displayed after students enter the live broadcast rooms at the beginning of the session. But one problem is that Ding Talk cannot show those students who have joined the class in the middle. Students who have not watched the live broadcast will only be displayed after the live broadcast ends, which is not conducive to the teacher's statistics on the students' lateness or absence.

The author's solution is to combine the online sign-in function of Chaoxing Learning system with the statistic function of Ding Talk. Initiate a sign-in on Chaoxing Platform ten minutes before each class begins, and set the class time to end the sign-in immediately, which effectively solves the problem of calculating the number of students who did not attend 
classes on time. For students who have not arrived in time, the teacher can give reminders in multiple ways, such as Ding Talk, Chaoxing notifications or WeChat etc., to ensure that every student arrives in class on time.

\subsection{Interactive Mode}

The biggest problem of distance teaching is how to carry out classroom interactions. The Massachusetts Institute of Technology in the United States once stated clearly for the school's online course platform that "If a student does not provide interactions with the school's teachers, and it is impossible for the student to obtain the school's certificates." [4] In the technical environment of online learning, the interactions in the teaching process are undoubtedly very important.

Although modern information technology provides equal learning opportunities for students of different abilities, it does not mean that all students can get the same educational experience. Years of experience in teaching reforms such as "flipped classrooms" have taught me that increasing effective classroom interaction is undoubtedly a strong promotion of learning experiences, and it has always been an important trend in the reform of higher education. During the current pandemic environment, the author believes that not only should we not reduce or even cancel interactions on the grounds of distance learning, but also emphasize the necessity of teacher-student interactions in the course of teaching. The reason is obvious. Compared with ordinary offline classrooms, it will be harder for teachers to accomplish the following tasks:

Firstly, supervise students' learning status. Many students can turn on the games and entertainment functions of their mobile phones when watching the live broadcast. If the teacher does not emphasize classroom interactions, it will be very hard for the students to conduct effective questions and offer answers, and therefore it is very likely that the teacher will only have a monologue while no one is virtually listening to him or her.

Secondly, effectively ensure that students enter the teaching process and achieve learning output. If there is no interactive link in distance teaching, it will be difficult for the teacher to detect whether students have understood a certain point of knowledge, and it is nearly 
impossible to ensure that students can follow the speed of teachers and achieve learning output. In particular, pure language courses such as college English are relatively theoretical. If the teacher only focuses on explaining basic knowledge such as texts without interactive links, it is easy for students to be lost in learning process and gradually give up learning, thus failing to achieve effective teaching effects.

So, how should the classroom interaction of distance learning be carried out? The author summarized the following countermeasures in practice to ensure the smooth progress of interaction in distance education:

Firstly, pay attention to the suspension of lectures, and put forward targeted selection questions.

When mentioning the preparation for screen recording in the previous article, the author emphasized the "ten-minute limit" of students' attention. Teachers are required to promptly ask some relevant questions about the content being taught, and keep students' listening status and enthusiasm in the form of online answers. Because it is an online live broadcast format, teachers are not suitable for asking too complicated questions. It is best to set up questions based on comparatively easy selections so that students can respond in time. Because the microphone connection function of Ding Talk Live is not so perfect, if it takes a long time to connect the microphones with students, it is not recommended here. The multiple-choice question is also very helpful for students to actively answer and can achieve effective classroom interaction.

TABLE 2 Online teaching data recorded by ZJOOC Platform

\begin{tabular}{|c|c|c|}
\hline \multirow{4}{*}{$\begin{array}{c}\text { Teaching } \\
\text { videos }\end{array}$} & Total number of videos & 34 \\
\cline { 2 - 3 } & Watch time(hours) & 28905 \\
\cline { 2 - 3 } & Total time(minutes) & 387.62 \\
\hline \multirow{3}{*}{$\begin{array}{c}\text { Other } \\
\text { resources }\end{array}$} & Total size of video resources & $13.49 \mathrm{G}$ \\
\cline { 2 - 3 } & Number of question banks & 139 \\
\cline { 2 - 3 } & Expansion information & 42 \\
\hline
\end{tabular}




\begin{tabular}{|c|c|c|}
\multirow{4}{*}{ Test } & Total number of tests & 3 \\
\cline { 2 - 3 } & Total number of exercises & 156 \\
\cline { 2 - 3 } & Test submission times (times) & 124 \\
\hline \multirow{4}{*}{ Homework } & The number of participants & 123 \\
\cline { 2 - 3 } & Total number of homework & 12 \\
\cline { 2 - 3 } & Total number of exercises & 15 \\
\hline \multirow{5}{*}{ Interaction } & Test submission times (times) & 1249 \\
\cline { 2 - 3 } & The number of participants & 126 \\
\cline { 2 - 3 } & Number of course announcements (times) & 2256 \\
\cline { 2 - 3 } & Total number of posts & 341 \\
\cline { 2 - 3 } & Total number of replies & 132 \\
\cline { 2 - 3 } & Total number of teacher's posts & 113 \\
\cline { 2 - 3 } & Total number of teacher's replies & 107 \\
\cline { 2 - 3 } & Number of people participating in the interaction & 5 \\
\hline
\end{tabular}

\subsection{The Correction of Homework}

The reasonable arrangement and effective correction of classwork is also an important part of distance teaching. The author has set up multiple homework forms to check the completion of students' learning by taking photos of homework, submitting audio, group discussion, and platform composition, so as to achieve the purpose of effective teaching effect supervision.

In addition, it is necessary to supplement and consolidate grammar and syntax composition exercises. It has been mentioned beforehand that the English homework function has been developed by Ding Talk during the pandemic. Teachers can arrange compositions on this platform by clarifying the requirements and publishing them on time. Ding Talk can remind students in the group and urge students to submit homework online on time. Teachers can also set up assignments, such as requirements, number of submissions, correction methods, viewing methods, and so on. With the support of the auxiliary function of "English homework" of Ding Talk, it will undoubtedly help break through the limitations of college English teaching and help teachers achieve "burden reduction". [5] 


\subsection{The Construction of Online Course}

Long-distance teaching may encounter network instability. Teachers need to make preparations for both "live broadcasting and recording" when operating remotely. The author uploads the micro-class videos and teaching materials to the cloud disk of the learning platform, and generates course chapters to ensure that students can watch the teaching videos according to the teacher's arrangement and study in combination with the teaching materials in the case of problems with the live broadcast system. Although the construction work is cumbersome, the benefits are obvious: when you have enough food in hands, so you don't panic in mind. With a complete reserve of recording materials, live broadcasts can be readily available to make online teaching smoother. The preparation of both recording and live broadcast is also sufficient for teachers to deal with various emergencies of online teaching, so that no matter what happens, students' study will be conducted normally. The guarantee of teaching content is undoubtedly the most important part of distance learning.

The combination of multi-platform sign-in guarantees the student attendance rate and class time. The effective development of classroom interaction triggers students' in-depth thinking. The arrangement of homework after class effectively consolidates the teaching effects. The recording of the course on the network platform effectively guarantees the development of teaching work. It increases the confidence of teachers to teach remotely, and provides better assistance to students' independent learning. The combination of all these methods helps teachers to complete online teaching tasks ideally.

\section{THE REFLECTIONS ON DISTANCE TEACHING PRACTICES}

With the advancement of this long-distance teaching, the author has gradually adapted to the new model of online teaching, and feels that the brand-new experiences are completely different from the previous offline teaching and the "flipped classroom" of teaching reform. At present, the nationwide fight against the epidemic is coming to an end. With the efficient command of the government and the collective efforts of the people across the country, the epidemic has been well controlled, and there have been no new additions for many days. 
It is very likely that a full resumption of work and school will be achieved in the coming April. In the following, the author will conduct a questionnaire survey of the teaching situation from the two aspects of the students and the group of the teachers in the course group, and conduct a basic survey of the teaching situation in the three weeks before the school starts from the perspective of students and teachers.

\subsection{The Questionnaire Survey for Students}

First of all, the author relied on the questionnaire function of Chaoxing to conduct a survey on the teaching class and the teaching situation in the first three weeks of school. Two multiple choice questions, one multiple choice question and one short answer questions are designed in the questionnaire. The author chose the two classes with 40 students and 33 students respectively with a total of 73 students. $100 \%$ of the students participated in this questionnaire survey. The results of the survey are shown in the figure below:

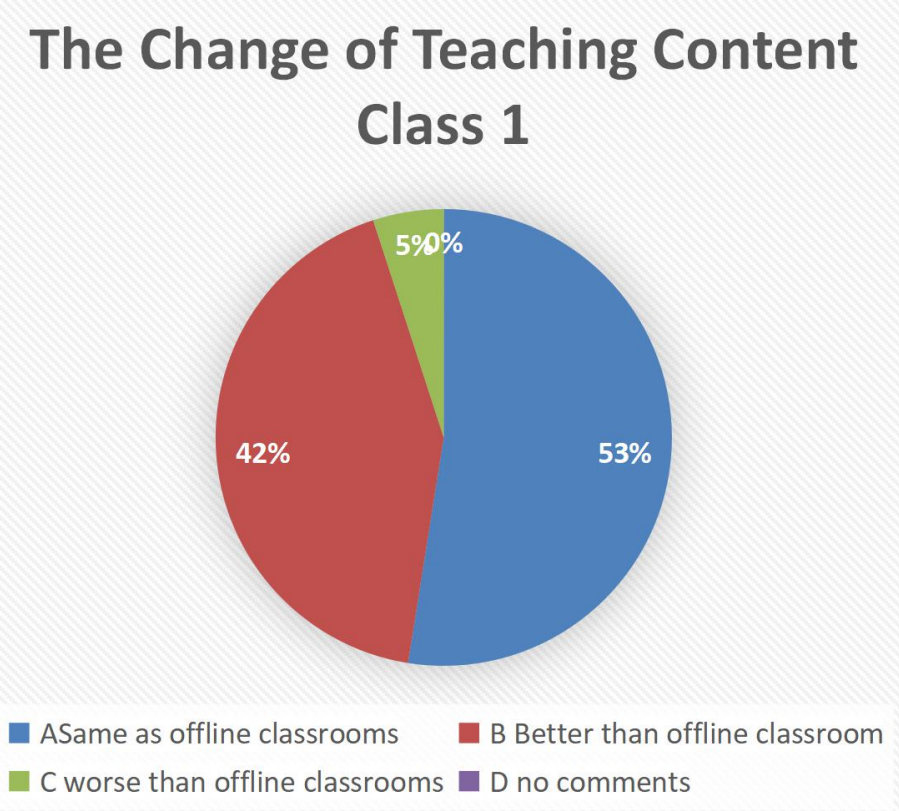

Figure 2 the Data of the Questionnaire Survey of the Teaching effects of Class 1 quoted from Chaoxing Learning Platform 


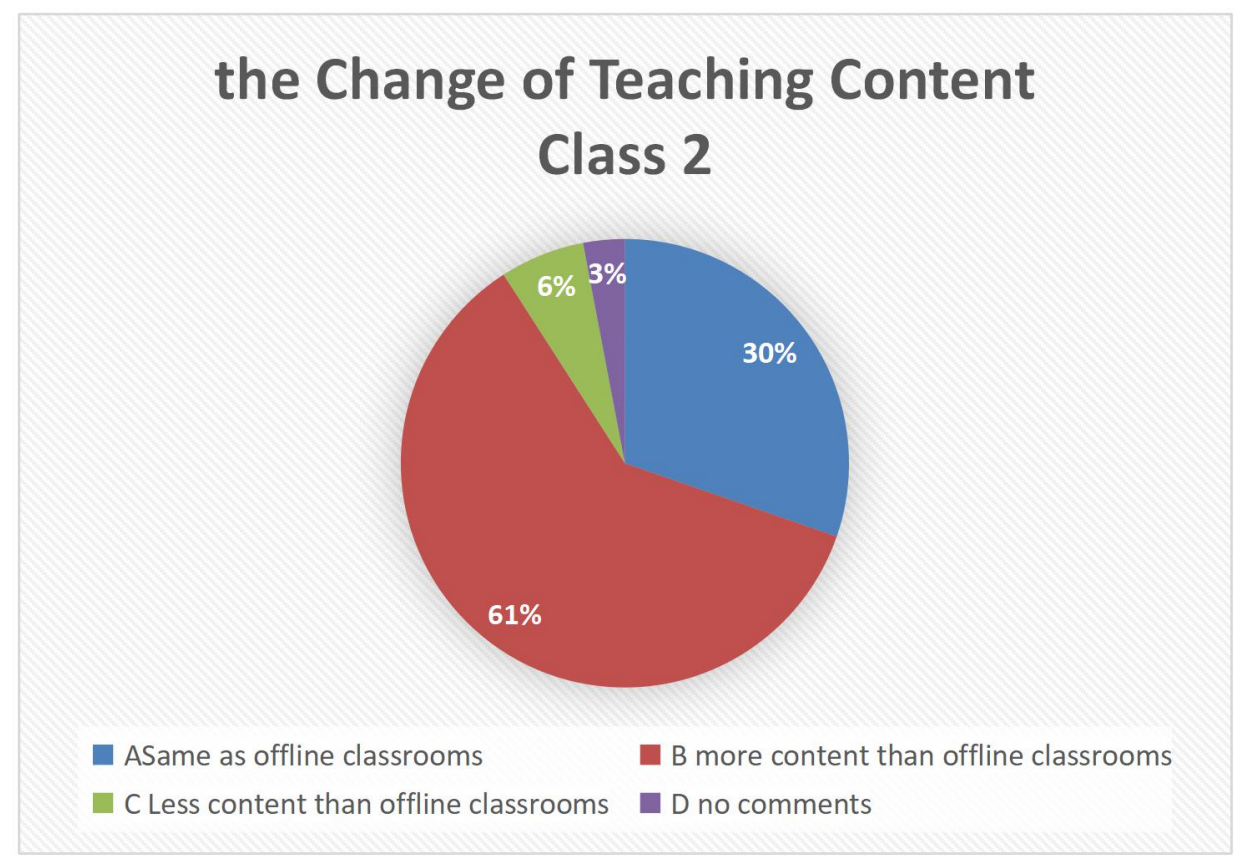

Figure 3 the Data of the Questionnaire Survey of the Teaching effects of Class 2 quoted from

\section{Chaoxing Learning Platform}

The first question is aimed at investigating whether or not the students have experienced the reduction of teaching content compared with the online classroom compared with the physical classroom. A total of 73 people from the two teaching classes participated in the questionnaire survey. Among them, $93.15 \%$ of the test students felt that the college English online courses this semester did not decrease in content compared with the previous physical classrooms. Among them, 31 people felt that the content did not decrease, and they felt that they were online. Classrooms are richer in content than the original physical classrooms, with 37 people in more diverse forms; among them, only 4 people think that the physical classroom content is reduced, and only one person who answered that I don't know. It can be seen that the vast majority of the tested students believe that the online teaching format did not have a negative impact on the completion of the teaching content, and even $50.68 \%$ of the students believe that due to the online format, the content of the original physical classroom teaching is richer. This is a great affirmation of this online teaching work. 


\section{The Problems of Distance Teaching Class 1}

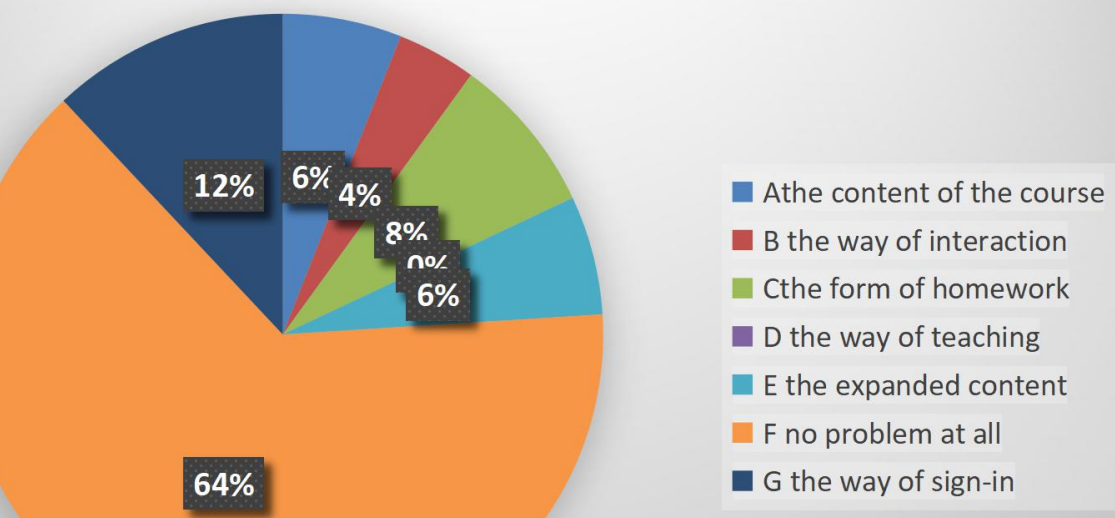

Figure 4 the Data of the Questionnaire Survey of the change of teaching content of Class 1 quoted from Chaoxing Learning Platform

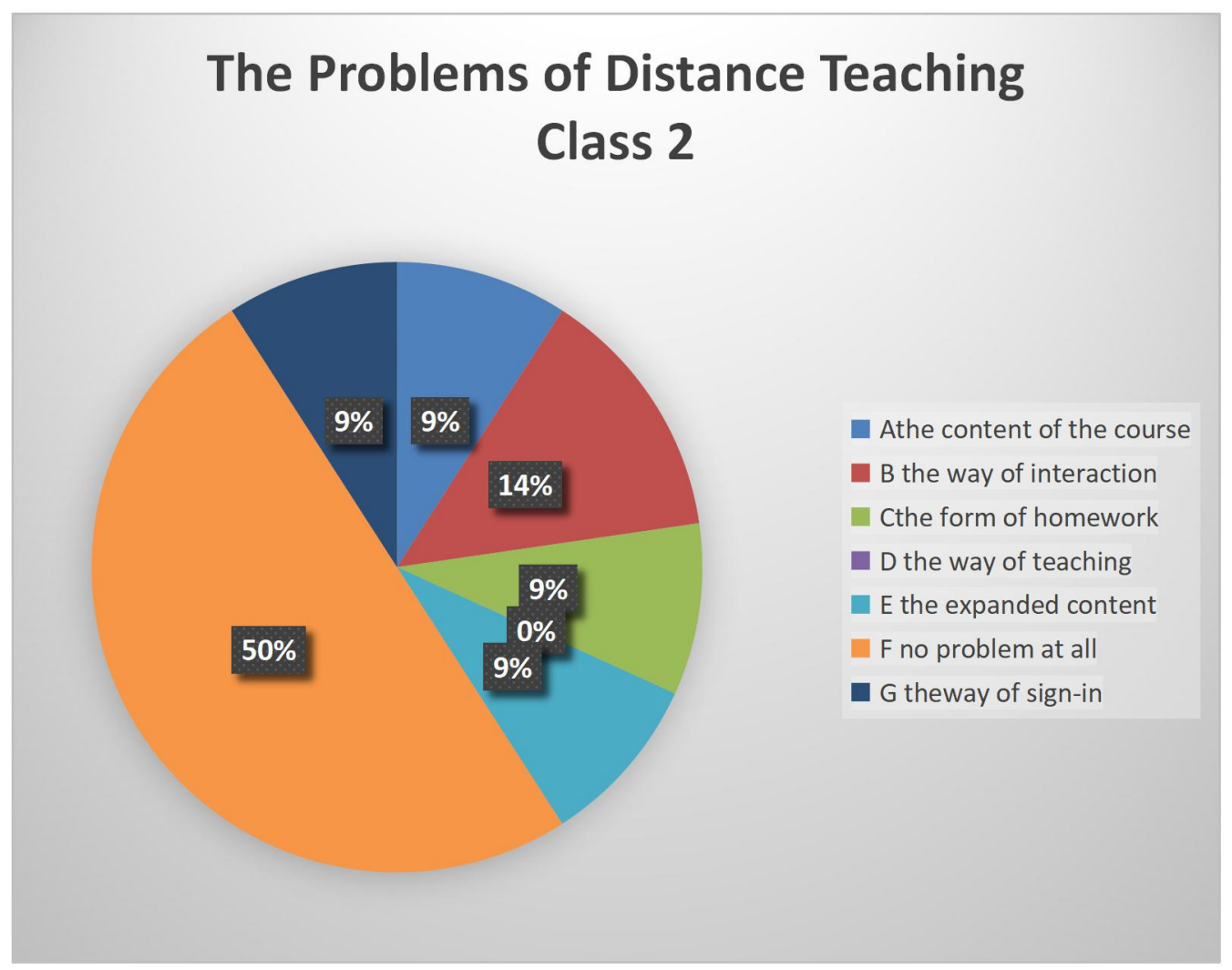

Figure 5 the Data of the Questionnaire Survey of the change of teaching content of Class 2 quoted from Chaoxing Learning Platform 
The second question of the questionnaire is set as a multiple-choice question, aiming at the aspects of the online classroom of "College English" that the students want to adjust. The 54 students who participated in the survey, accounting for $73.97 \%$ of the total number of the two teaching classes, believed that "no adjustment is needed", which is also a great support and affirmation of the work at this stage. In addition to this option, the test students think that the most important thing to improve is the sign-in method. At this point, the author has adopted sign-in methods on various multi-platforms (Chaoxing, Ding Talk and We Chat group), and the sign-in function of Chaoxing will be combined with Ding Talk live classroom function to ensure that every student can enter the classroom on time and on point, and successfully complete every teaching task.

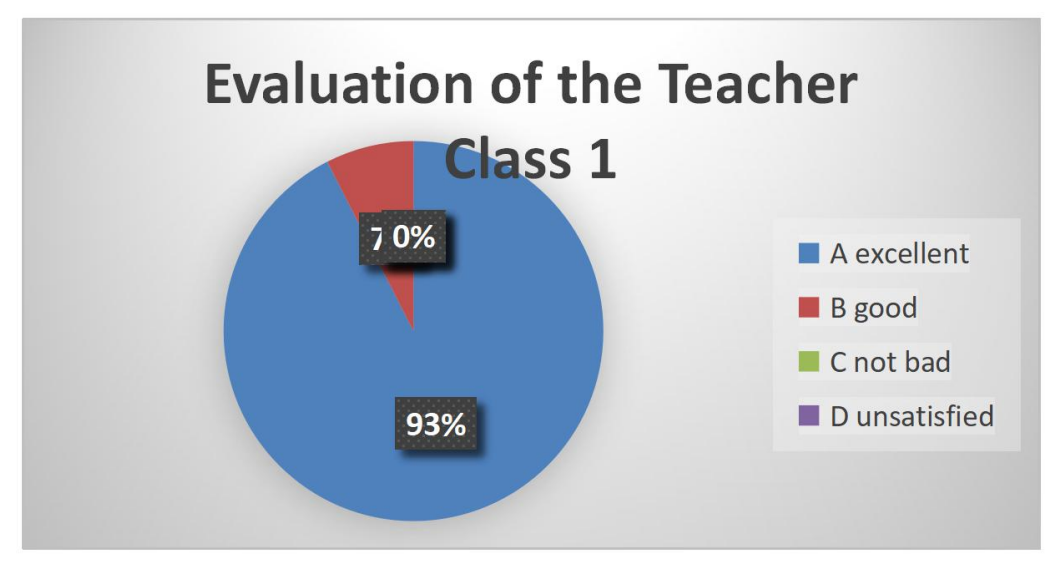

Figure 6 the Data of the Questionnaire Survey of the evaluation of the teacher in Class 1 quoted from Chaoxing Learning Platform

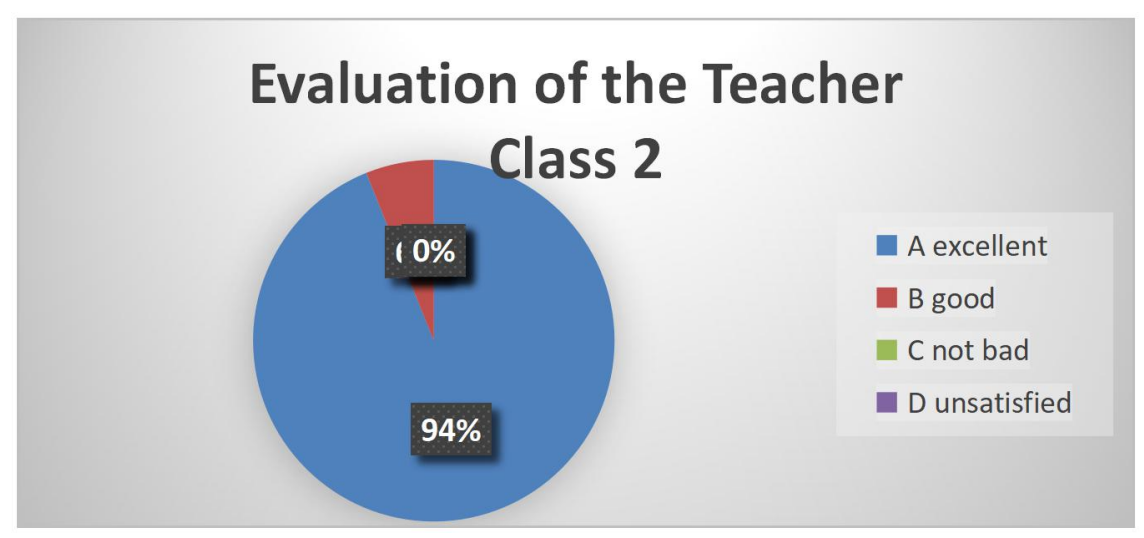

Figure 7 the Data of the Questionnaire Survey of the evaluation of the teacher in Class 2 quoted from Chaoxing Learning Platform 
The third question of the questionnaire is a single-choice question, in which students are invited to evaluate their satisfaction with the teaching method of the teacher. Among them, $93.15 \%$ of the test students think that the teacher's online teaching mode is very good, which makes them very satisfied. $6.84 \%$ of the subjects thought they were quite satisfied, and none of them chose general or unsatisfactory. This is also a great affirmation of the teaching method of the teacher.

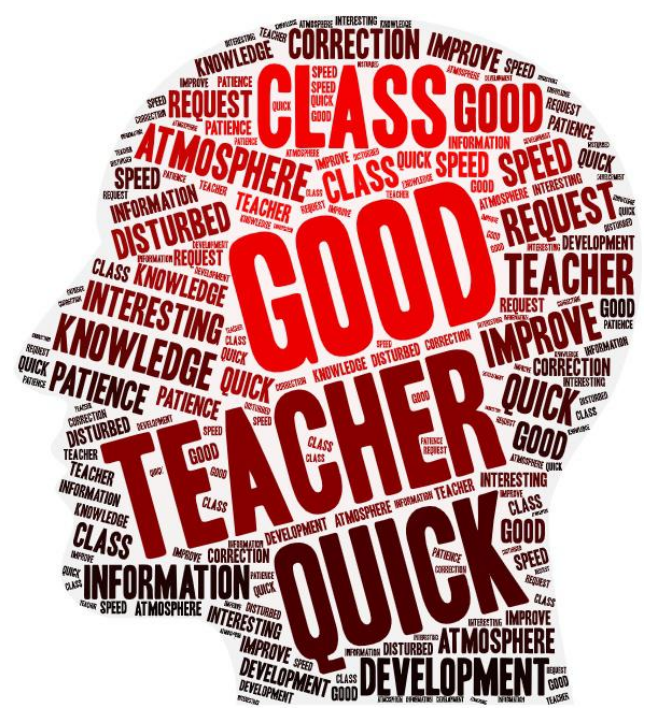

Figure 7 the Data of the Questionnaire Survey of Subjective Question of Class 1 quoted from Chaoxing Learning Platform

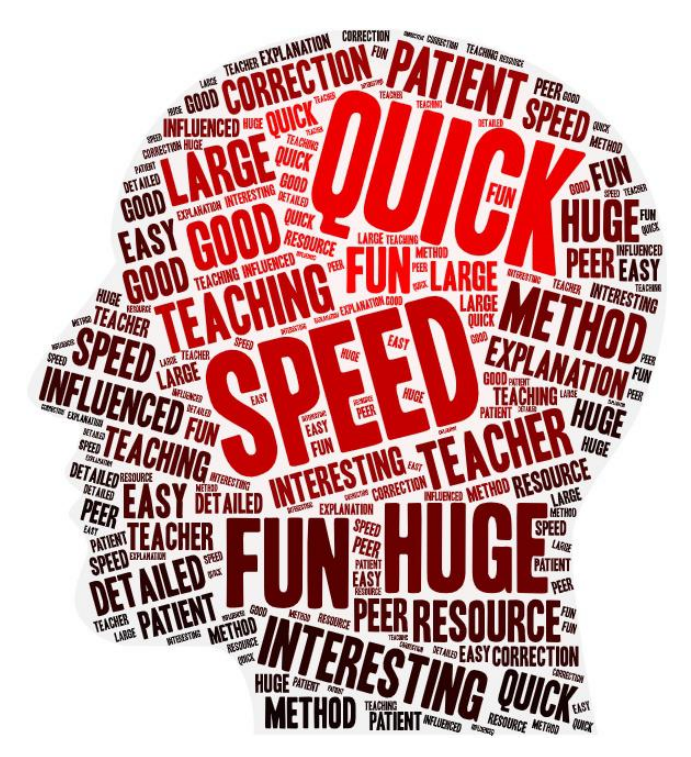

Figure 8 the Data of the Questionnaire Survey of Subjective Question of Class 2 quoted from Chaoxing Learning Platform 
The last question of the questionnaire is a subjective question, and students are invited to put forward their opinions and requirements for this online teaching. The vast majority of students recognized the teaching mode used by the author in this online teaching, such as multi-platform sign-in, multi-way answering, etc. Among them, the top keywords for the Chinese language class are "good teacher"”, “quick response", "high intensity", "requirement" and "good classroom" have been pointed out by individual students who have suggested that online teaching requires too much on network conditions, and the speed of the Internet at home has affected the interaction in class. The top keywords in the safety and advertising class are "quick answer, "speed” , "appropriate", "very good”, “fun”, “favorite” and other positive words. Some students think that online classes require students to face a long time after all. Compared with offline classrooms, computers or mobile phone screens are easier to distract the attention of students. To address this problem, on the one hand, teachers need to design more interactive links to enhance the attractiveness of teaching content to stimulate students' interest in learning; on the other hand, it is necessary for both teachers and students to actively respond to the organic integration of Internet information technology and education, and emphasize the self-discipline and consciousness of online learning. [6]

\subsection{The Questionnaire Survey for the Teaching Group}

In addition to the questionnaire survey conducted by the students in the class, the author also conducted a questionnaire survey for the teachers of the course group. 19 teachers participated, and the participation rate was $100 \%$. With the questions such as "the choice of the most commonly used interactive methods", "the biggest challenge encountered in class", the author aimed to understand the thoughts and opinions of the teachers of this course group in the distance teaching in the three aspects and to carry out deep reflections on the online teaching mode. 


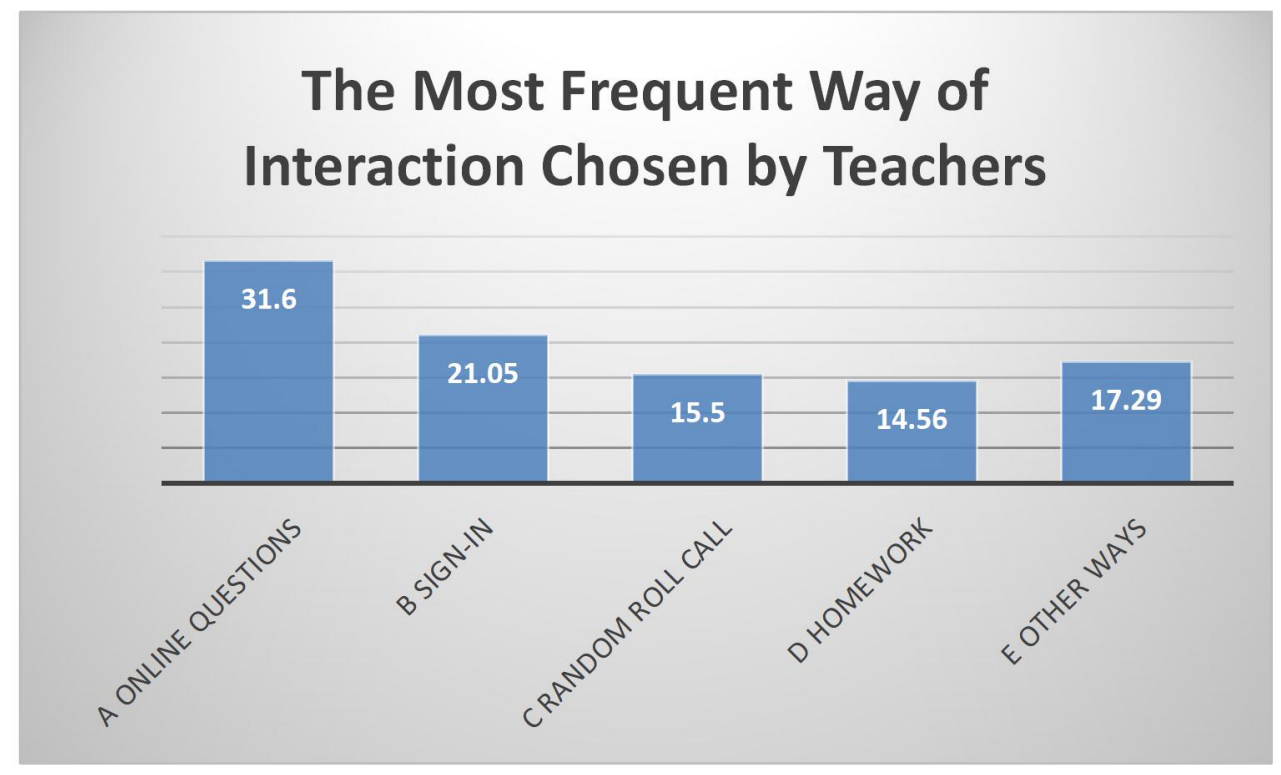

Figure 9 The most Frequent way of interaction chosen by teachers

As is shown in Figure 6, 31.6\% of course group teachers tend to set up questions online, requiring students to answer online to interact. The setting of questions is mainly based on selection, which is convenient for students to answer online and can detect the effect of the previous stage of teaching. It can also ensure that students listen carefully online. Platform sign-in and random roll call are also the online interactive mode that teachers like to use, accounting for $36.55 \%$. Only $14.56 \%$ of teachers choose homework interaction. Most teachers will still choose appropriate online teaching methods for interaction based on "local" conditions.

\subsubsection{The Biggest Challenge Encountered in Distance Teaching}

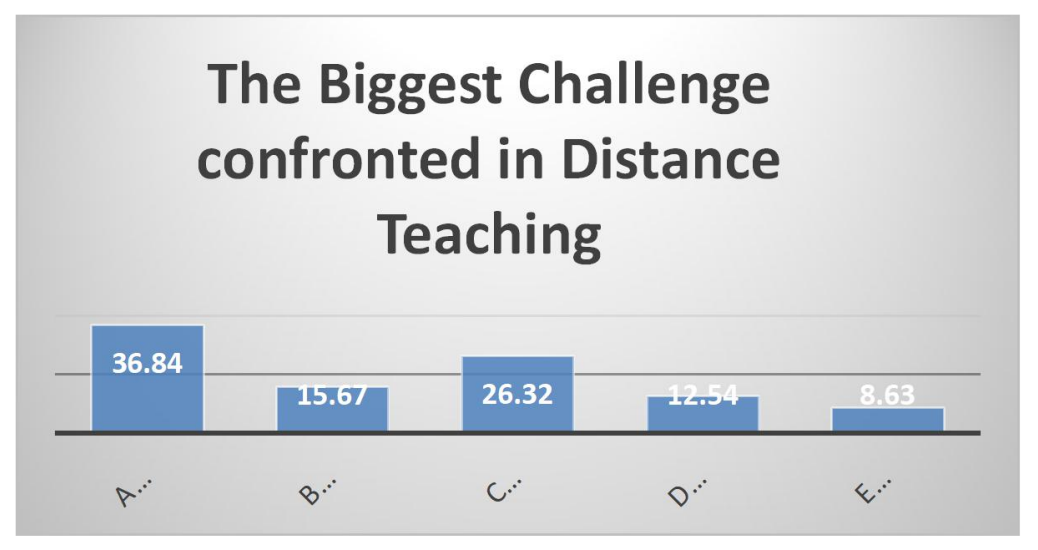

Figure 10 The Biggest Challenge confronted in Distance Teaching 
As shown in the figure, the teachers of the course group believe that the most important online teaching difficulty lies in the supervision of teaching effects and lesson preparation, accounting for $36.84 \%$ and $26.32 \%$ respectively. Due to the sudden outbreak of the epidemic, some teachers did not prepare textbooks and teaching PPT in advance, and most teachers did not have experience in online classes before. How to effectively and orderly carry out online teaching has become an important issue. Furthermore, teachers are required to make preparation online, which undoubtedly poses a challenge to the teacher community.

\subsubsection{The average daily working hours of online classes for teachers of the course group}

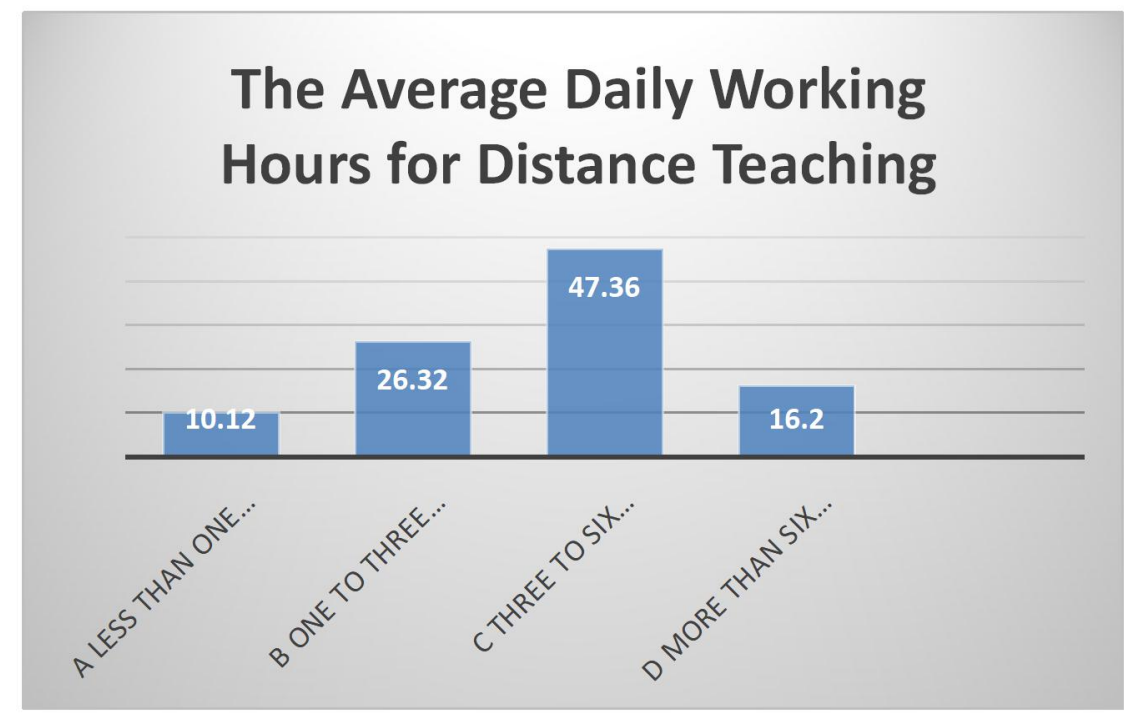

Figure 11 The average daily working hours for distance teaching

As shown in the figure, due to the unfamiliarity with online teaching methods, most teachers need to spend more time to prepare courses than offline classes. In the first three weeks of online teaching, teachers who need to spend 3-6 hours a day It accounts for the highest proportion, reaching $47.36 \%$, preparing for online teaching content, homework assignments, and homework corrections. The average daily working hours of more than 6 hours accounted for the second place, reaching 26.32\%. Although the Ding Talk platform launched the "English homework" function during the epidemic, it has not yet reached the level of manual correction. Online composition still requires teachers to manually point out expressive problems. At the same time, the news and translations submitted by students on the Internet also require teachers to spend a lot of time to collect and correct. 


\subsection{The Summary of the Survey}

Based on the above questionnaire survey of students and teachers, combined with personal online teaching preparation and teaching practical work experience, the author makes the following summary:

\subsubsection{The Cooperation at All Levels of Teaching}

Since the outbreak of the epidemic started suddenly, teachers were in the winter vacation and were not mentally prepared for online teaching tasks. How to smoothly carry out remote online teaching and how to make online teaching reach the quality of offline classroom teaching is undoubtedly a huge challenge for teachers, students and also the universities.

At the university level, school leaders quickly made emergency arrangements. The Director of the Academic Affairs Office supervised all teachers to familiarize themselves with the mainstream online teaching platform as soon as possible, and invited the technical personnel of the school's cooperation platform and professors with online teaching experience provide online teaching guidance for all teachers in the form of Ding Talk Live broadcast.

At the college level, faculty and department leaders made detailed arrangements for the beginning of the online semester, and urged all teachers to make specific preparations for the online start of school, and so on.

At the level of the course group, the We-Chat group of the course group has been set to offer mutual assistance for each other. The information sharing between colleagues has effectively solved many practical problems in distance teaching, such as the determination of the teaching format, the teaching platform, the selection of teaching methods, the sharing of teaching methods, the exchange of teaching reflections, and so on.

At the level of teachers, teachers use the winter vacation to complete a number of pre-class preparations, design the micro-class teaching content, and select teaching resources suitable for online teaching.

At the student level, teachers and students establish We-Chat group to have effective interactions, which helps teachers to obtain feedback from students in time, helps to obtain 
feedback from students in time, and calms students' anxiety and so on. It is the conscientious and conscientious cooperation of the staff at all levels involved in teaching that can guarantee the orderly and smooth progress of this remote teaching work.

\subsubsection{The Inevitable Trend of Educational Informatization}

Educational informatization is an inevitable path for the reform and development of college education. Online teaching puts forward higher requirements for the modern working ability of college teachers. The progress and development of informatization will inevitably lead to related changes in teacher education, and how to recognize one's position in this change will determine the teacher's own development and the quality of education and teaching. [7] Colleges and universities can appropriately incorporate the practice of effective use of technology to support teaching into the evaluation system of teacher career promotion. Whether the teaching goals and technology costs are achieved should be regarded as important dimensions of the evaluation criteria. [8] Local colleges and universities have formulated and issued some encouraging policies to guide teachers to find their own development paths in the direction of teaching informatization, which undoubtedly meets the needs of education reform in the digital age.

The effective implementation of online classrooms is also inseparable from teachers' learning and mastery of modern educational technology. The inadequate and inactive use of information technology by college teachers has become a new obstacle to the informatization of education. [9] Teachers should actively and actively use information technology in teaching, such as actively designing teaching micro-classes, interactive links, and being familiar with the operation of online platforms. Under the influence of the undergraduate education reform actions that have continued since the end of the 20th century, the hours devoted to teaching by college teachers have been steadily increasing. [10] Judging from the survey feedback data from the course team teachers during the epidemic, teachers will undoubtedly need to spend more time and energy than physical teaching to organize online teaching. College teachers must psychologically adapt to this change in teaching thoughts and functions. [11] 


\subsubsection{The Reflection on the Practices and Effects of Distance Online Teaching}

Teachers' timely reflections on the practices and effects of this remote online teaching will help to improve the traditional teaching model. Judging from the feedback from students of the online teaching practices, the use and operation ability with educational technology greatly affects the teaching effects of online classrooms. In addition to being a teacher, a university teacher is also a researcher of teaching mode. If the teaching process is carefully reviewed by the teacher, it can show the most outstanding characteristics in the overall function. [12] Therefore, teachers should require themselves as researchers, reflect on teaching practices in time, and evaluate the effects of technical support teaching, so that they can better conduct information teaching in the future.

Reflecting on the teaching practices, the author has realized the following points:

Firstly, MOOC Resources on Ding Talk and other learning platforms can help students break through the time limit and can be stored for a long time for free use by students, which undoubtedly gives full play to the value of course resources. [13]

Secondly, because teachers have adopted a teaching model suitable for online courses and made changes in sign-in, classroom interactions, and homework processing, it is obvious that some students who are not active in offline classrooms are more active in online learning.

Undoubtedly, teachers' ability to use information technology greatly affects the teaching effect of online classrooms. Teachers should evaluate the effect of technology-supported teaching, and use the successful experience of this online teaching as an important basis for guiding and improving physical teaching. [14] After the pandemic crisis is over, the author will continue to study educational technology, use Chaoxing, Ding Talk, etc. as auxiliary tools in offline classrooms, and make full use of the online platforms to sign in, post, answer questions and vote. Undoubtedly, those interactive functions will, to a large extent, enhance the interactions in the offline classrooms. 


\section{CONCLUSION}

With the continuous advancement of the prevention and control of the COVID-19 pandemic, everything is developing for the better. In order to achieve better prevention and control purposes, the distance teaching in colleges and universities across the country may continue for some time. The above-mentioned summary of the experience of distance teaching practices may help teachers have the confidence to guide students to successfully complete this special stage of learning tasks and realize the educational work of colleges and universities. It is no denying that our nation will completely win this nationwide battle against the epidemic in the near future.

From a global perspective, the harm of the crisis should not be underestimated. Until March 24, 2020, the cumulative number of confirmed cases worldwide has exceeded 210 thousand. Many countries have increased their epidemic prevention efforts and have adopted online distance education. In this context, the sustainable advancement of online education is undoubtedly still facing major tests. [15] It is worthwhile for more and more college teachers to actively explore the possibility of the integration of network information, communication technology and education, so that in the future, there can be more flexible ways to solve the problems of distance education in emergencies.

\section{REFERENCES}

[1] Yang XX, Chen DB, et al. Teaching and Learning from the Perspective of "Internet + Education”. Teaching and Management, 2017;6: 26.

[2] Horn M.B, Staker H. Blended using disruptive innovation to improve schools. San Francisco: Wiley, 2015:15-18.

[3] Wang P. The Analysis of Learners' learning Habits Based on edX Open Data. Modern Education Technology, 2015;4:92. 
[4] Jiang $\mathrm{X}$, Hong $\mathrm{M}$. The Innovation and Future of U.S. Higher Education Informationization-A Review of the Planning of Reshaping the Role of Technology in Higher Education. Modern Education Management, 2019;3:117.

[5] Zhang N. Probe into the Teaching Mode of College English Flipped Class under the Background of MOOC. Heilongjiang Science, 2017;4:131.

[6] Future Ready Learning: Rethinking the Role of Technology in Education, National Education Technology Plan 2016. Washington D C : U. S. Department of Education [EB/O L]. [2016-03-13].http://tech.ed.gov.

[7] Jiang $\mathrm{X}$, Hong $\mathrm{M}$. The Innovation and Future of U.S. Higher Education Informationization-A Review of the Planning of Reshaping the Role of Technology in Higher Education. Modern Education Management, 2019;3:119.

[8] Yang XX, Chen DB, et al. Teaching and Learning from the Perspective of "Internet + Education". Teaching and Management, 2017;6: 24.

[9] Jiang X, Hong M. The New Development of the U.S. Teacher Education Information Policy-Comments on the Federal Government's Promoting the Application of Educational Technology in Teacher Training. Journal of Jimei University (Educational Science Edition), 2019;4:2.

[10] Guo H, Yao Y. Changes of a Decade in the Relationship between Teaching and Scientific Research of Research University Teachers. China Higher Education Research,2020;2:79.

[11] Dong LL. Practice and Research of MOOC in College English Translation Teaching. Contemporary Teaching and Research Essays, 2018;6: 12.

[12] Lin XY, Song X. Promoting the "Excellent Teaching" of University Teachers: From Behaviorism to Reflective Recognition. Peking University Education Review, 2014;2:47.

[13] Wang JJ. Application of MOOC in College English Translation Course Teaching. Shaanxi Higher Education, 2019;5: 52. 
[14] Jiang X, Hong M. The Innovation and Future of U.S. Higher Education Informationization-A Review of the Planning of Reshaping the Role of Technology in Higher Education. Modern Education Management, 2019;3:119.

[15] Chen XB , Yang XX. The "Digital Divide" in Online Education Era. Educational Observation, 2018;7:138. 